\title{
Planificación turística, promoción y sostenibilidad ambiental: el caso de España
}

\section{Tourism planning, promotion and environmental sustainability: the case of Spain}

Dra. Marta Plumed Lasarte es profesora/investigadora de la Universidad Nebrija, Directora del Postgrado Online en Turismo y Responsable de Títulos Propios del Área de Turismo (España) (mplumed@nebrija.es) (http://orcid.org/00000002-8463-0477)

Dra. Diana Gómez Bruna es profesora/investigadora de la Universidad Nebrija, Directora del Departamento de Turismo (España) (dgomezb@nebrija.es) (http://orcid.org/0000-0003-2578-3593)

Dra. Clara Martín Duque es profesora/investigadora de la Universidad Nebrija, Directora del Postgrado en Turismo (España) (cmartidu@nebrija.es) (http://orcid.org/0000-0002-9270-7200)

\begin{abstract}
Resumen
En el desarrollo sostenible de un destino turístico, la planificación juega un papel fundamental, y parte importante recae en la promoción turística. En el caso de España, el boom turístico de los años 50 supuso un alto nivel de ingresos y popularidad, pero también serios perjuicios en el entorno cuando todavía no se prestaba atención a la sostenibilidad turística. Para que el desarrollo turístico de un destino sea sostenible es necesaria la implantación de planes estratégicos adecuados, y este trabajo permite, gracias al estudio de un caso real, analizar la influencia de la promoción turística en la evolución de un destino turístico hacia la sostenibilidad. La metodología empleada ha sido doble: en primer lugar se han revisado documentos oficiales del Gobierno español para comprobar la evolución de su planificación turística en torno a la sostenibilidad y, en segundo lugar, se han analizado imágenes y campañas de promoción turística para comparar la evolución de la imagen transmitida y su influencia en el desarrollo sostenible del turismo español. Este análisis demuestra que la promoción turística ha jugado un papel muy importante en el desarrollo y crecimiento de España como destino turístico, y que su adaptación a las necesidades del mercado y a la sostenibilidad resultó fundamental. Se confirma por tanto que la promoción turística, dentro de una estrategia general de planificación, es cuestión clave para un correcto desarrollo de un destino turístico.
\end{abstract}

\begin{abstract}
In terms of tourist destination's sustainable development, planning plays a key role, and an important part is the tourist promotion. In the case of Spain, the boom of tourism in the 50s meant a high level of income and popularity but also serious damage in the environment when tourist sustainability didn't receive attention yet. For the tourist development of a destination to be sustainable, the establishment of appropriate strategic plans is needed. Thus, thanks to the study of a real case, this paper allows the analysis of the influence of tourist promotion in the evolution of a tourist destination towards the sustainability. The method used has been double: firstly, Spanish government's official documentation has been reviewed in order to confirm the evolution of Spanish tourist planning in relation to sustainability; secondly, tourist promotion images and campaigns has been analyzed to verify the evolution of the conveyed image and its influence in the sustainable development of Spanish tourism. This analysis confirms that tourist promotion has played a main role in the development and growth of Spain as a tourist destination, proving that its adaptation to market's needs and sustainability was fundamental. Therefore, it is verified that tourist promotion -within a general planning strategy- means a key aspect for an appropriate development of a tourist destination.
\end{abstract}

\section{Palabras clave I keywords}

Sostenibilidad, turismo, promoción, planificación.

Sostenibility, tourism, promotion, planning.

Forma sugerida de citar: Plumed Lasarte, M., Gómez Bruna, D. \& Martín Duque, C. (2018). Planificación turística, promoción y sostenibilidad ambiental: el caso de España. Retos Revista de Ciencias de la Administración y Economía, 15(8), 7-18. https://doi.org/10.17163/ret.n15.2018.01 


\section{Introducción}

En los últimos años el concepto de sostenibilidad se ha ido implantando en casi todas las áreas de conocimiento. En relación con el turismo, numerosos congresos, libros y estudios científicos han analizado el turismo sostenible y su importancia para los destinos (Fernández, 2015). Aunque el turismo sostenible implica no sólo la protección del medio ambiente sino también la viabilidad socioeconómica a largo plazo, el primer aspecto es el que normalmente recibe más atención y a él se dedica principalmente el presente trabajo. En ocasiones, en el ámbito turístico surge la controversia sobre el daño que el turismo puede provocar en el medio ambiente. Sin embargo, esto ocurre cuando existe una falta de planificación. Desarrollo turístico y sostenibilidad pueden coexistir siempre que haya una adecuada estrategia para proteger el medio ambiente (García y Díaz, 2014). De hecho, el turismo puede incluso motivar la protección de recursos naturales, como ocurre con la declaración de espacios protegidos como los Parques Nacionales, por ejemplo. Aplicar la sostenibilidad a la planificación turística es fundamental, y en un destino turístico líder como es España ya lo relataban los Ministerios implicados en 1999, al indicar que los destinos deben proteger sus recursos naturales para ser competitivos a largo plazo (Ministerio de Economía y Hacienda, y Ministerio de Medio Ambiente, 1999), considerando asimismo el respeto a la población local y a los territorios anexos.

De la misma forma que el desarrollo sostenible debería ser uno de los objetivos de cualquier política y acción general, los gestores responsables del desarrollo turístico deberían entender que es necesario poner límites a lo que se puede conseguir a corto y medio plazo (Bramwell et al., 1996). El turismo sostenible anima a los destinos y a las empresas a prestar atención a los impactos que el turismo tiene sobre el medio ambiente y demuestra la importancia de la conservación de los recursos naturales.

En España, el boom turístico de finales de los 50 supuso un alto nivel de ingresos y popularidad internacional, pero también un alto impacto en el medio ambiente. La respuesta de España al elevado interés de turistas europeos en busca de sol y playa supuso el sobredimensionado desarrollo a lo largo de la costa española, siendo uno de los más claros ejemplos de las consecuencias del turismo de masas (OMT y ETC, 2009). Ser un destino popular de sol y playa supuso para España una construcción no planificada de grandes edificios, áreas residenciales y nuevas instalaciones, sin pensar en el impacto medioambiental. A todo ello hay que sumar que la densidad de población de las localidades costeras españolas es cinco veces mayor que la media nacional y se triplica durante la temporada alta (Vogeler \& Hernández, 2003), siendo el impacto poblacional uno de los aspectos más importantes a considerar en el desarrollo sostenible (Castrillón et al., 2015).

A menudo se asume que la planificación turística desarrollada por el sector público debe jugar un papel mayor en el desarrollo del turismo sostenible, ya que las campañas y estrategias de marketing llevadas a cabo tendrán un impacto en los destinos (Swarbrooke, 1999). La promoción de España como destino turístico ha jugado un papel fundamental en la evolución de su imagen y el tipo de productos turísticos que, desde el Gobierno, se tratan de promocionar. Durante los años 80, el Gobierno español tomó la valiente decisión de dar un giro en su estrategia, centrando sus campañas internacionales en el turismo interior y cultural (OMT \& ETC, 2009), reposicionando su imagen y creando una marca turística con un logotipo que aún perdura. No resulta difícil darse cuenta de los cambios y la evolución que han ido llevando las diferentes 
campañas de promoción, principalmente tras la creación de la mencionada marca en 1984. El objetivo de este artículo es analizar la relación entre la promoción turística y la sostenibilidad a través de una aproximación cualitativa del caso de España gracias a la metodología descrita a continuación.

\section{Metodología y fuentes de información}

Para ilustrar con ejemplos cómo la promoción de un destino turístico puede influir en la sostenibilidad de un territorio, se ha tomado España como referencia debido a su larga trayectoria en la elaboración de estrategias de marketing y su destacado «re-branding», que no sólo mantiene su tradicional mercado de sol y playa, sino que además ha ido introduciendo a España en nuevos mercados (OMT \& ETC, 2009) de una forma más sostenible.

En primer lugar, con el fin de conocer los objetivos de los diferentes planes y su relación con la sostenibilidad, se ha llevado a cabo un análisis descriptivo a partir de la información obtenida de fuentes secundarias sobre TURESPAÑA ${ }^{1}$ y la planificación turística en general, analizando su evolución a través de documentos oficiales desarrollados por el Gobierno central para mejorar la competitividad de España como destino turístico y su sostenibilidad, tales como:

- $\quad$ Planes de competitividad (1992, 1996): Plan Marco de Competitividad del Turismo Español 1992-1995 (FUTURES I) y Plan Marco de Competitividad del Turismo Español 1996-1999 (FUTURES II).

- Plan de Estrategias y Actuaciones de la Administración General del Estado en Materia Turística (1997).

- $\quad$ Plan Integral de Calidad del Turismo Español 2000-2006 (PICTE) (2000)

- $\quad$ Plan del Turismo Español Horizonte 2020 - Plan 2008-2012 (2007, 2012)

- $\quad$ Plan Nacional e Integral de Turismo 2012-2015 (PNIT) (2012)

En segundo lugar, se ha tratado de localizar imágenes no sólo de las campañas oficiales de TURESPAÑA desde la creación de la marca en 1984, sino también de acciones promocionales del Gobierno desarrolladas con anterioridad, pudiendo así observar su evolución desde el boom turístico de los años 50 hasta los últimos años. Para ello, se ha llevado a cabo un análisis descriptivo y comparativo de las diferentes campañas, estudiando en cada una de ellas los mensajes transmitidos y sus objetivos, para así poder comparar y ver en detalle la evolución de la imagen de España y su influencia con su sostenibilidad como destino turístico.

\section{Análisis y resultados}

\subsection{Política turística en España}

La primera normativa relacionada con turismo en España data de 1905, pero es en 1951 cuando se crea el primer Ministerio de Turismo, llamado «Ministerio de Información y

1 Organismo público responsable de la promoción turística de España a escala internacional. 
Turismo» (Tena, 2006). En ese momento, España ya comenzaba a ser un destino popular, lo cual creó la necesidad de tener una entidad que organizara el fenómeno turístico español. Sin embargo, el rápido e intenso crecimiento de la actividad turística y su novedad en el país -sin precedentes legislativos-, dio lugar a una industria sin planificar que fue ganando fuerza de forma rápida y descontrolada.

No hay mención específica a ningún concepto relacionado con la sostenibilidad en los planes políticos hasta FUTURES I, en el que encontramos ciertas referencias a la conservación del medio ambiente (Velasco, 2010). La evolución de las consideraciones relacionadas con la sostenibilidad en política turística se dio cronológicamente de la siguiente manera:

- FUTURES I (1992-1995). A través de este plan de competitividad, el Gobierno estableció nuevas estrategias para consolidar el turismo como un sector económico, prestando atención a sus impactos, especialmente a nivel ambiental. Entre sus objetivos podemos encontrar uno en concreto que habla sobre la conservación del medio ambiente natural y urbano y su compatibilidad con la actividad turística (Secretaría General de Turismo, 1992).

- FUTURES II (1996-1999). Este plan incluyó un programa de nuevos productos que consideraba la sostenibilidad de los proyectos en relación con el medio ambiente. Este segundo plan competitivo sí menciona el concepto «sostenibilidad» como punto clave y considera el modelo de sostenibilidad en el desarrollo de destinos turísticos (Secretaría General de Turismo, 1995a).

- Plan de Estrategias y Actuaciones de la Administración General del Estado en Materia Turística (1997). Una de las estrategias de este plan trata sobre el desarrollo del concepto de sostenibilidad medioambiental, e incluye entre sus objetivos el impulso de «planes de turismo sostenible» en destinos turísticos y la incorporación de la gestión ambiental en las empresas turísticas (Secretaría General de Turismo, 1995b).

- PICTE (2000). Uno de sus principales objetivos fue la sostenibilidad medioambiental de las actividades turísticas y, dentro de su programa sobre calidad de destinos, hay un punto específico sobre sostenibilidad y la necesidad de prestar atención a los límites de crecimiento en algunas áreas turísticas y a la cooperación entre agentes turísticos y medioambientales con el objetivo de establecer aspectos sostenibles a largo plazo (Secretaría General de Turismo, 2000).

- Plan del Turismo Español Horizonte 2020 - Plan 2008-2012 (2007). En este plan, el concepto de sostenibilidad es un aspecto fundamental y uno de los elementos básicos del modelo central. Uno de sus objetivos fue mejorar la sostenibilidad del modelo turístico español, asegurando la calidad del entorno natural y aplicando el concepto de sostenibilidad a todas las decisiones turísticas (Secretaría General de Turismo, 2007, 2012).

- $\quad$ PNIT (Plan Nacional e Integral del Turismo) 2012-2015 (2012). Con este último plan, el Gobierno central pretendía promover una nueva visión de España, incluyendo la sostenibilidad como una necesidad para ser un destino competitivo. Siguiendo esta línea, el plan incluyó una evaluación de la oferta turística española con el objetivo de asegurar una gestión y un desarrollo sostenible de la misma (Secretaría de Estado de Turismo, 2012). 
Como se puede ver, la evolución de la importancia de la sostenibilidad en la política turística es positiva en la planificación de políticas públicas en España. En el periodo de mayor crecimiento turístico del país no hubo mención a ningún concepto relacionado con la sostenibilidad, y por ello el desarrollo turístico español no tuvo planificación y por tanto graves perjuicios para el medio. Sin embargo, cuando el Gobierno español comprendió la importancia de la gestión sostenible del turismo, los planes políticos empezaron a cambiar su percepción de la actividad turística y la influencia de la sostenibilidad en el desarrollo del turismo fue obteniendo un papel cada vez más fundamental. Esta evolución positiva se refleja en la proyección de la imagen de España como destino turístico, ya que los planes y programas están implicados en su promoción turística, que se analiza a continuación.

\subsection{TURESPAÑA}

El Instituto de Turismo de España (TURESPAÑA), creado en 1990, es un organismo dependiente del Gobierno central encargado de promocionar España en el extranjero como destino turístico. La sostenibilidad es uno de los aspectos que el Gobierno quiere promover y por ello, entre sus principales áreas de acción, encontramos: "el desarrollo de los planes y programas que promuevan la innovación, la calidad, la sostenibilidad y la competitividad de productos turísticos" (BOE, 2009). Además, es importante mencionar que TURESPAÑA es la herramienta más importante de la política turística española, ya que no se limita únicamente a la promoción de la oferta turística sino que también presta atención a aquellas áreas que pueden tener un efecto negativo en la sostenibilidad turística (TURESPAÑA, web). Para ello tiene una Subdirección General de Desarrollo y Sostenibilidad Turística, responsable de la creación de estrategias enfocadas al desarrollo y la mejora de la planificación y gestión sostenible de los destinos turísticos (BOE, 2009).

La política turística desarrollada por TURESPAÑA fundamentalmente trata de conservar el potencial de los destinos españoles con el compromiso de valorar la importancia del entorno y así reducir el desequilibrio socioeconómico y turístico de los territorios (TURESPAÑA, web). Sin embargo, el principal objetivo de TURESPAÑA es la promoción de España a nivel internacional, para lo cual desarrolla campañas consecutivas con el objetivo de transmitir una imagen positiva de España como destino turístico. En el siguiente epígrafe se analizan no sólo las campañas de TURESPAÑA sino también las acciones promocionales desarrolladas antes de su creación.

\subsubsection{Evolución de la promoción turística española}

Irónicamente, antes de que comenzara la popularidad de España como destino turístico, las campañas promocionales desarrolladas por el Gobierno enfatizaban no sólo el turismo de sol y playa, sino también los aspectos culturales e históricos del país (figura 1), ya que el objetivo era atraer turistas culturales de un alto nivel económico. 
Figura 1. Ejemplos de carteles turísticos de España en la década del cuarenta
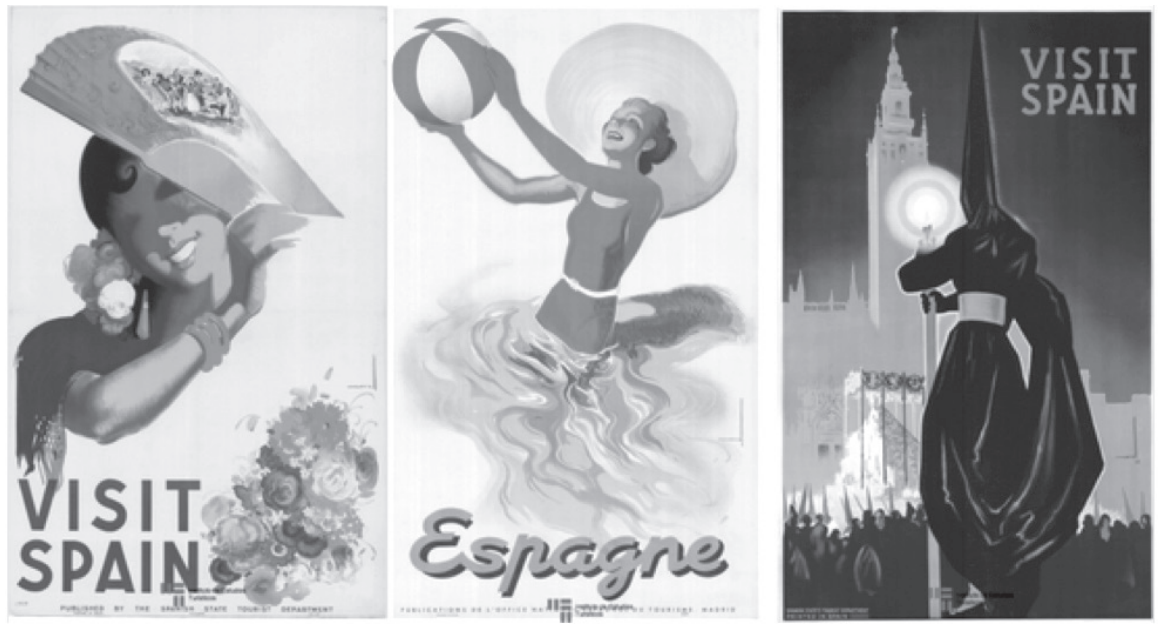

Fuente: Blog Turistario - El País.

Durante los años 50, el turismo en España comenzó a crecer rápidamente y el Gobierno creó un primer eslogan que se haría muy popular y que aún hoy se recuerda: «Spain is different» (figura 2). Esta nueva campaña, aunque continuó con la promoción cultural, comenzó a destacar el turismo de sol y playa, que era el que entonces se demandaba desde el extranjero y, por ello, sería la única imagen que se proyectara durante años.

Figura 2. Ejemplos de la campaña «Spain is different»
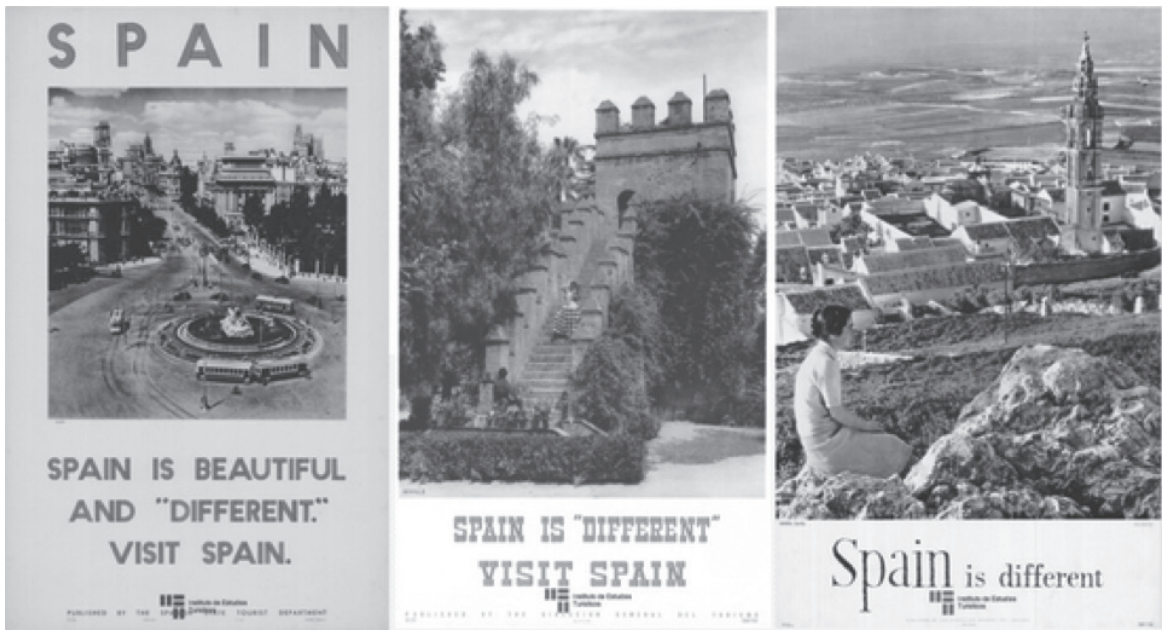

Fuente: Blog Turistario - El País. 
El eslogan «Spain is different» tuvo tanto éxito que trascendió más allá del turismo y se convirtió en una definición popular del carácter español. La clave de ese éxito radica en el uso del folclore como aspecto característico aprovechando los estereotipos de forma positiva, lo que hizo que el mensaje permaneciera en la memoria de los españoles no sólo como eslogan turístico, sino también como aspecto característico de ese período histórico (Plumed, 2012). Sin embargo, a pesar del éxito reflejado en el crecimiento de la actividad turística, la estrategia no estaba bien definida y aprovechar la popularidad de un único producto turístico demostró ser una gestión insostenible. Incluso cuando el Gobierno intentó promocionar nuevos productos como el turismo de negocios, las campañas usaban la imagen de sol y playa como elemento base (figura 3).

Figura 3. Ejemplo del aprovechamiento del producto de sol y playa en la promoción de destino de negocios

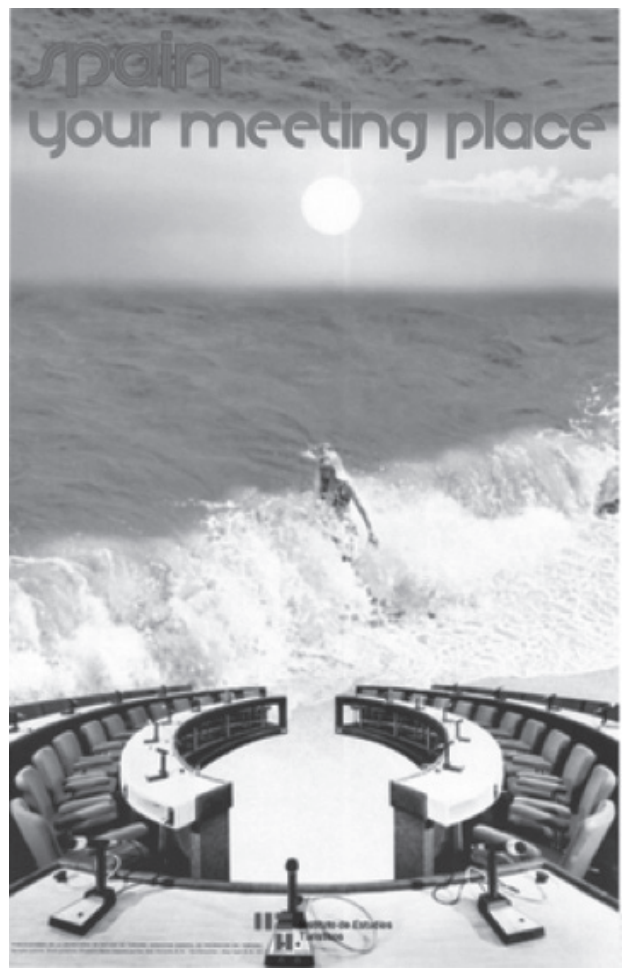

Fuente: Blog Turistario - El País.

Durante la década de los 80, el Gobierno decidió invertir más dinero y esfuerzo en la promoción turística, y fue en 1984 cuando se creó el logo oficial («El sol de Miró»), que aún hoy se conserva (figura 4). Este hecho dio paso a una nueva etapa en la promoción turística de España, ya que desde ese momento se comenzó a usar una misma marca a nivel internacional, lo cual supuso un gran avance en las campañas 
de marketing españolas, principalmente porque inició su recorrido en los años 80 y actualmente sigue en puestos líderes de imagen de marca. El logo de Miró está presente en todos los elementos de comunicación desarrollados por TURESPAÑA y se ha convertido en seña de identidad del turismo español.

Figura 4. Logo de la marca turística española: El Sol de Miró

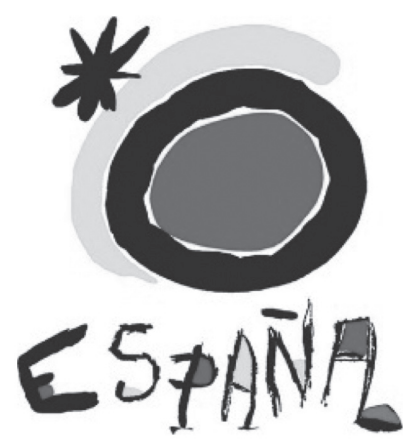

Fuente: TURESPAÑA (web).

Desde ese momento, las campañas oficiales comenzaron a desarrollarse de forma consecutiva de la siguiente manera (según información obtenida de la web de TURESPAÑA):

- 1984-1990: «España. Todo bajo el sol». Este claim fue creado con base en la privilegiada posición de España como destino turístico de sol y playa, pero con el objetivo de promocionar toda la diversidad de su oferta turística, tratando de demostrar que en España se podía realizar cualquier tipo de turismo, aunque en el propio claim se incluyera el concepto del sol.

- 1991-1994: «Passion for life». Esta campaña fue el resultado de un estudio realizado en ese momento para conocer la imagen de España. Dicho análisis demostró que España debía «venderse» como un país activo y vivo, sin seguir mencionando el clima y promocionando todo tipo de turismo, con el objetivo de evitar la estacionalidad y aprovechar las tendencias turísticas del momento. De esta manera, España trataba de entrar en mercados más sostenibles, destacando los esfuerzos del Gobierno por conservar los recursos naturales.

- 1995-1997: «Spain by...». Esta breve campaña incluyó fotografías realizadas por fotógrafos profesionales populares de aquel momento, reflejando sus diferentes formas de ver España. De nuevo, se intentaba no centrar la atención en el modelo de sol y playa.

- 1998-2001: «Bravo Spain». El objetivo de esta campaña fue transmitir una imagen moderna, creativa e innovadora de un país con oferta turística a lo largo de todo el año. De esta forma, el Gobierno seguía evitando la imagen de sol y playa ya que su objetivo no era aumentar la cantidad de turistas, sino la calidad de los 
mismos y su distribución a lo largo de toda la geografía española, lo cual es fundamental para el desarrollo de un turismo sostenible.

- 2002-2003: «Spain marks». Esta campaña también pretendía distanciar la imagen de España del modelo de sol y playa como única oferta turística. En este caso lo hizo transmitiendo la idea de que visitar España es una experiencia única que cambia al turista. Con este mensaje, TURESPAÑA pretendía mostrar un destino turístico diferente gracias a la alta calidad de su oferta cultural, gastronómica y de naturaleza.

- 2004-2009: «Smile! You are in Spain». En este caso la campaña se creó con el objetivo de consolidar el liderazgo de España como destino vacacional pero también posicionarse como destino cultural de alta calidad para desarrollar un turismo basado en la diversificación del producto y la redistribución geográfica. Con esta estrategia el Gobierno seguía intentando conseguir un equilibrio entre los diferentes tipos de turismo y que la actividad turística no se centralizara en la costa.

- 2008-2010: "Spain. 25 years beyond the sun». En este periodo se creó una campaña especial debido al $25^{\circ}$ aniversario del logotipo de Miró y de la marca turística oficial de España. Con ésta se trató de nuevo de dejar la imagen de país de sol y playa a un lado, lo cual se percibe en el propio claim que expone literalmente "más allá del sol", dando la idea de que España ofrece mucho más como destino turístico.

- 2010-2017: «I need Spain». Este claim sigue destacando valores similares a campañas anteriores, aunque esta vez usando un mensaje más cálido para llegar a diferentes tipos de turista, mostrando varios estilos de vida y vendiendo no sólo destinos sino también las emociones que éstos evocan.

Analizando todas las campañas referenciadas ut supra, se aprecia que el Gobierno ha tratado de transmitir una imagen de España diferente a lo largo de los años, alejada de la imagen de destino vacacional de sol y playa. A pesar de que algunos carteles promocionales todavía muestran las playas y algunos claims mencionan el sol, el mensaje ha ido evolucionando, principalmente desde que el Gobierno introdujo el concepto de sostenibilidad en la gestión de los destinos turísticos.

\section{Conclusión}

La sostenibilidad se ha convertido en un aspecto fundamental de la gestión turística, y los gobiernos de cada destino turístico deberían tenerlo en cuenta en su planificación de políticas turísticas. Podemos conocer las consecuencias de una gestión poco sostenible del turismo a partir del caso de España, donde un crecimiento rápido y no planificado de su actividad turística generó serios daños en el medio ambiente, principalmente en la costa española. Los otros tipos de sostenibilidad, relacionados con los aspectos sociales y económicos, que no han sido considerados en este trabajo, tienen la misma relevancia.

Algunos datos demuestran que el turismo español aún depende de los productos de sol y playa: los meses con mayor número de turistas siguen siendo julio y agosto -correspondiente al verano- (INE, 2016a) y el gasto realizado por los turistas 
en «turismo de sol y playa» es el más alto tras el indicador general de «ocio, recreo y vacaciones» (INE, 2016b), lo que demuestra que la imagen de España como destino turístico todavía está relacionada con ese tipo de oferta, lo cual explica que el Gobierno siga promocionando ese tipo de productos. Sin embargo, la imagen de España como destino cultural está creciendo: el gasto en el rubro de "turismo cultural» creció un 6,5\% en 2016 (INE, 2016b), lo que demuestra que la oferta turística de un país posicionado puede diversificarse con el objetivo de mejorar la calidad de su industria turística, gestionándola de una forma más sostenible.

Parece claro que ya nadie pone en duda el impacto del turismo sobre el medio en el que tiene lugar, y esa preocupación es lo que ha llevado a conceptos tan empleados hoy en día como sostenibilidad, desarrollo sostenible o turismo sostenible. La necesidad de encontrar ese equilibrio entre actividad turística y sostenibilidad lleva a tratar de lograr una gestión responsable del territorio y de los recursos, que a su vez motiva a la búsqueda, por parte de los organismos responsables, de métodos de planificación a diferentes escalas. Se impone una redefinición de los destinos hacia segmentos de mayor valor añadido, ya que la sostenibilidad tiene un retorno de inversión claro y, si atendemos a la conservación de los recursos, urge llevar la sostenibilidad a todos y cada uno de los procesos de la industria turística, y que además se comunique mejor (Fernández, 2015).

Analizando la evolución de la política y la promoción turística de España, se percibe cómo la gestión sostenible puede influir en la industria turística y cómo los mensajes transmitidos en las diferentes campañas tienen también influencia en la imagen del destino. Ser sostenible es ser competitivo, y tener una imagen positiva es la clave para tener un buen posicionamiento. Así, la relación existente entre sostenibilidad y promoción turística pasa por una adecuada planificación turística, siendo el Gobierno el principal responsable del hecho de considerar la sostenibilidad como aspecto fundamental.

\section{Referencias}

BOE-Boletín Oficial del Estado (2009). Real Decreto 561/2009, de 8 de abril. Madrid: Ministerio de la Presidencia.

Bramwell, B., Henry, I., Jackson, G., Prat, A.G., Richards, G., \& Straaten, J. (Eds.) (1996). Sustainable Tourism Management: Principles and Practice. Tilburg: Tilburg University Press.

Castrillón, I. D., Canto, A. G., Cantorna, A. S., \& Cerradelo, L. B. (2015). Análisis de los principales modelos explicativos de la competitividad de los destinos turísticos en el marco de la sostenibilidad. CULTUR-Revista de Cultura e Turismo, 5(2), 101-124.

Fernández, J. F. (2015). El turismo sostenible en España: análisis de los planes estratégicos de sostenibilidad en el ámbito local. Tesis Doctoral. Universidade da Coruña.

García, J. R., \& Díaz, M. M. (2014). Planificación turística y desarrollo sostenible. Septem Ediciones.

Gosálvez, P. (2011). España en tres palabras: De "Spain is different" a "I need Spain". Blog Turistario - El País. (https://goo.gl/BT8vgr)

INE-Instituto Nacional de Estadística (2016a). Movimientos turísticos en fronteras, 2016. Madrid: Instituto Nacional de Estadística.

INE-Instituto Nacional de Estadística (2016b). Gasto turístico, 2016. Madrid: Instituto Nacional de Estadística.

Ministerio de Economía y Hacienda, \& Ministerio de Medio Ambiente (1999). Un turismo sos- 
tenible. Madrid: Ministerio de Economía y Hacienda, Ministerio de Medio Ambiente.

Plumed, M. (2012). The evolution of the image of Spain as a tourist destination. European Journal of Tourism, Hospitality and Recreation, 3 (Special Issue), 215-233

Secretaría General de Turismo (1992). Plan Marco de competitividad del turismo español: 19921996. Madrid: Ministerio de Industria, Comercio y Turismo.

Secretaría General de Turismo (1995a). Plan Marco de Competitividad del Turismo Español: 19961999. Madrid: Ministerio de Comercio y Turismo.

Secretaría General de Turismo (1995b). Programa turismo, desarrollo y medio ambiente: la sostenibilidad como referencia, informe final. Madrid: Secretaría General de Turismo.

Secretaría General de Turismo (2000). Plan Integral de Calidad del Turismo (PICTE). Madrid: Ministerio de Economía y Hacienda.

Secretaría General de Turismo (2007). Plan del Turismo Español. Horizonte 2020. Avance del Plan. Madrid: Ministerio de Industria, Turismo y Comercio

Secretaría General de Turismo (2012). Plan del Turismo Español Horizonte 2020. Plan de Turismo Español 08-12. Madrid: Ministerio de Industria, Turismo y Comercio.

Secretaría de Estado de Turismo (2012). Plan Nacional e Integral de Turismo. Madrid: Ministerio de Industria, Energía y Turismo.

Swarbrooke, J. (1999). Sustainable Tourism Management. Oxon: CAB International.

Tena, V. (2006). Fundamentos del Derecho Administrativo del Turismo. Revista de Derecho Administrativo, 9(5), 319-341.

TURESPAÑA (website) (https://goo.gl/iZcwKz) (03-2013).

Velasco, M. (2010). La incorporación de ideas en las políticas públicas, el concepto de sostenibilidad en la política turística. Revista de Análisis Turístico, 10(2), 35-44.

Vogeler, C., \& Hernández, E. (2003). El mercado turístico. Estructura, operaciones y procesos de producción. Madrid: Editorial Centro de Estudios Ramón Areces, S.A.

OMT \& ETC-Organización Mundial de Turismo y European Travel Commission (2009). Handbook on Tourism Destination Branding. Madrid: World Tourism Organization. 